\title{
New Nrf2-Inducer Compound ITH12674 Slows the Progression of Retinitis Pigmentosa in the Mouse Model rd10
}

\author{
Laura Campello Oksana Kutsyr ${ }^{\mathrm{a}} \quad$ Agustina Noailles ${ }^{\mathrm{a}}$ Patrycja Michalskac,d,e \\ Laura Fernández-Sánchez ${ }^{\dagger} \quad$ Natalia Martínez-Gila Isabel Ortuño-Lizarána \\ Xavier Sánchez-Sáez ${ }^{a} \quad$ Emilio de Juan ${ }^{a}$ Pedro Lax ${ }^{a}$ Rafael Leónn ${ }^{c, d e}$ \\ Antonio G. Garcíac,dee Nicolás Cuenca ${ }^{a} \quad$ Victoria Maneu ${ }^{f}$ \\ aDepartamento de Fisiología, Genética y Microbiología, Universidad de Alicante, Alicante, Spain, \\ ${ }^{b}$ Neurobiology-Neurodegeneration and Repair Laboratory, National Eye Institute, National Institutes \\ of Health, Bethesda, MD, USA, Instituto Teófilo Hernando, Universidad Autónoma de Madrid, Madrid, \\ Spain, ${ }^{D}$ Departamento de Farmacología y Terapéutica, Facultad de Medicina, Universidad Autónoma \\ de Madrid, Madrid, Spain, eInstituto de Investigación Sanitaria, Hospital Universitario de la Princesa, \\ Universidad Autónoma de Madrid, Madrid, Spain, fDepartamento de Óptica, Farmacología y Anatomía, \\ Universidad de Alicante, Alicante, Spain
}

\section{Key Words}

Neuroprotection • Neurodegeneration • Retina • Retinitis pigmentosa • Compound ITH12674

\begin{abstract}
Background/Aims: It is well established that oxidative stress and inflammation are common pathogenic features of retinal degenerative diseases. ITH12674 is a novel compound that induces the transcription factor Nrf2; in so doing, the molecule exhibits anti-inflammatory, and antioxidant properties, and affords neuroprotection in rat cortical neurons subjected to oxidative stress. We here tested the hypothesis that ITH12674 could slow the retinal degeneration that causes blindness in rd10 mice, a model of retinitis pigmentosa. Methods: Animals were intraperitoneally treated with 1 or $10 \mathrm{mg} / \mathrm{Kg}$ ITH12674 or placebo from P16 to P30. At P30, retinal functionality and visual acuity were analyzed by electroretinography and optomotor test. By immunohistochemistry we quantified the photoreceptor rows and analyzed their morphology and connectivity. Oxidative stress and inflammatory state was studied by Western blot, and microglia reactivity was monitored by flow cytometry. The blood-brain barrier permeation of ITH12674 was evaluated using a PAMPA-BBB assay. Results: In rd10 mice treated with $10 \mathrm{mg} / \mathrm{Kg}$ of the compound, the following changes were observed (with respect to placebo): (i) a decrease of vision loss with higher scotopic a- and b-waves; (ii) increased visual acuity; (iii) preservation of cone photoreceptors morphology, as well as their synaptic connectivity; (iv) reduced expression of TNF- $\alpha$ and NF-KB; ( v) increased

L. Campello, O. Kutsyr and A. Noailles contributed equally to this work.

Victoria Eugenia Maneu Flores $\quad$ Department: Óptica, Farmacología y Anatomía, University of Alicante Carretera San Vicente del Raspeig s/n, San Vicente del Raspeig, Alicante, 03690 (Spain) Tel. +34 965903903, E-Mail vmaneu@ua.es
\end{abstract}




\section{Cellular Physiology Cell Physiol Biochem 2020;54:142-159 \\ \begin{tabular}{ll|l} 
and Biochemistry & DOl: 10.33594/000000210 & P 2020 The Author(s). Published by \\
Published online: 7 February 2020 & Cell Physiol Biochem Press GmbH\&Co. KG
\end{tabular} \\ Campello et al.: Novel Nrf2 Inducer ITH12674 Slows Retinal Degeneration}

expression of p38 MAPK and Atg12-Atg5 complex; and (vi) decreased CD11c, MHC class II and CD169 positive cell populations. Conclusion: These data support the view that a Nrf2 inducer compound may arise as a new therapeutic strategy to combat retinal neurodegeneration. At present, we are chemically optimising compound ITH12674 with the focus on improving its neuroprotective potential in retinal neurodegenerative diseases.

(C) 2020 The Author(s). Published by

Cell Physiol Biochem Press GmbH\&Co. KG

\section{Introduction}

Retinal photoreceptor degeneration occurs in various pathological disorders such as age-related macular degeneration (AMD) or diabetic maculopathy; in these conditions, death of macular photoreceptors results in central vision loss. On the other hand, in a third pathological entity, retinitis pigmentosa (RP), the widespread photoreceptor degeneration across the entire retina ends with total blindness. Disease cell pathogenesis in these conditions is incompletely understood; and this is why treatments that slow down or arrest disease progression are not yet clinically available [1,2].

Studies on human retinopathy and in animal models of RP revealed chronic neuroinflammation with increasing retinal levels of proinflammatory cytokines [3, 4]. Also, microglial infiltration causes photoreceptor loss due to cytokine secretion and apoptosis $[5,6]$. Hence, agents that mitigate microglial contribution to neuroinflammation and to photoreceptor degeneration are promising as potential therapeutic agents in RP [6].

A few studies addressed some targets of RP pathogenesis, in order to look for photoreceptor protection. For instance, the modulator of estrogen receptors tamoxifen decreased microglia activation and inflammation, with rescue of photoreceptor structure and function [7]. Additionally, the natural phenolic acid from Kalimeris indica 3, 4-dihydroxybenzoate (MDHB), displays antioxidant, antiapoptotic, and neuroprotective effects [8]; the compound also affords photoreceptor protection in rd10 mice [9]. Another natural compound, sulforaphane, present in cruciferous vegetables such as broccoli, Brussel sprouts and cabbages also exhibits antioxidant and antiinflammatory properties; these are linked to its ability to activate the nuclear factor erythroid 2-related factor 2 (Nrf2). In one study, the compound protected retinal pigment epithelial cells against photooxidative damage [10]; in a second study, sulforaphane protected against retinal degeneration in Pde6 (rd10) RP mice [11].

These results support the hypothesis that the pharmacological induction of Nrf2 could be a good strategy to mitigate oxidative stress and neuroinflammation, with ensuing neuroprotection. In this context, we synthesized compound ITH12674 $\left(\mathrm{C}_{12} \mathrm{H}_{12} \mathrm{~N}_{2} \mathrm{SO}\right.$; Fig. 1). In a previous in vitro study, the compound decreased the production of reactive oxygen species (ROS) with increased glutathione concentrations, and afforded neuroprotection against oxidative stress. These effects were associated to Nrf2 induction [12]. As part of a program to develop Nrf2 inducers as neuroprotective agents, we planned the present study to establish the in vivo proof-of-concept of ITH12674 as neuroprotectant. We therefore tested the compound by its chronic administration to RP rd10 mice. We found that indeed, ITH12674 afforded retinal neuroprotection in the retina of rd10 mice, both at morphological and functional levels. These data are essential in the frame of our research program of chemical ITH12674 optimisation, from the points of view of neuroprotective efficacy, and its pharmacokinetic-safety profiles.

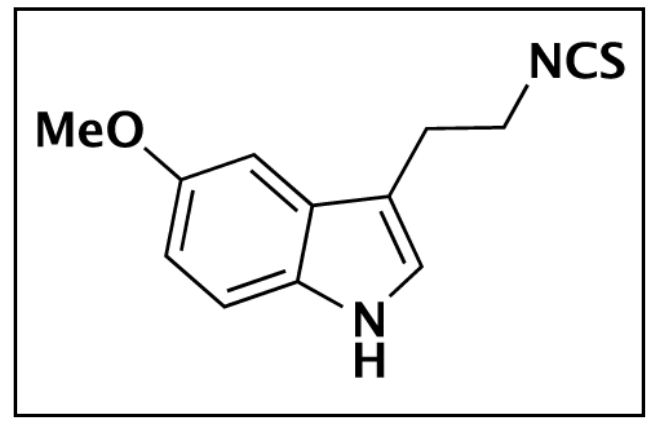

Fig. 1. Chemical structure of ITH12674. 


\section{Cellular Physiology Cell Physiol Biochem 2020;54:142-159 \begin{tabular}{c|c|c|c|c|}
\hline Dol: 10.33594/000000210 2020 The Author(s). Published by & \\
\hline
\end{tabular} and Biochemistry Published online: 7 February 2020 Cell Physiol Biochem Press GmbH\&Co. KG \\ Campello et al.: Novel Nrf2 Inducer ITH12674 Slows Retinal Degeneration}

\section{Materials and Methods}

\section{Animals}

Both male and female homozygous rd10/rd10 mice (B6.CXBI-Pde6brd10/J) were used. Age-matched wild- type C57BL/6J mice (Harlan Laboratories, Barcelona, Spain) served as reference. Animals were handled and maintained according to current guidelines and regulations for the use of laboratory animals (NIH, ARVO and European Directive 2010/63/EU) and comply with the Reporting of in vivo Experiments (ARRIVE) guidelines of animal research, in an effort to minimize their suffering and limit the number of animals used. All procedures received prior approval from the ethics committee for animal care and use at the University of Alicante (UA-07/22/2013). Animals were bred and maintained in the animal facilities of the University of Alicante under controlled temperature (23 $\pm 1{ }^{\circ} \mathrm{C}$ ), humidity $(60 \%)$ and light/dark cycle (12:12 h, 50 lux) conditions. Animals were humanely sacrificed at P30 and samples were collected for further analysis.

\section{Drug administration}

ITH12674 in a water soluble cyclodextrin complex formulation [13] was administered intraperitoneally at 1 or $10 \mathrm{mg} / \mathrm{kg}$ twice a day from P16 to P30. A total of 26 animals were used, spread in 3 batches: (1) control: rd10 mice injected with saline (vehicle) (n=7), (2) ITH $1 \mathrm{mg} / \mathrm{kg}$ : rd10 mice treated with $1 \mathrm{mg} / \mathrm{kg}$ ITH12674 (n=4), (3) ITH 10 mg/kg: rd10 mice treated with 10 mg/kg ITH12674 (n=15).

\section{Electroretinographic records}

Scotopic flash-induced ERG responses were recorded in both eyes after treatment completion (P30), as described previously [14]. Briefly, following an overnight period of dark adaptation light stimuli were administered by a Ganzfeld stimulator for $10 \mathrm{~ms}$ at 11 increasing luminances, ranging from -5.2 to $0 \log \mathrm{cd} \mathrm{s} / \mathrm{m}^{2}$. To test the cone contribution to the ERG responses, double flashes with intensity of 0 $\log \mathrm{cd} \mathrm{s} / \mathrm{m}^{2}$ and interstimulus intervals of $1 \mathrm{~s}$ were applied after each range of single flashes. Around 3 and 10 consecutive recordings were averaged for each light level. A 10-s interval was provided between flashes in the case of dim flashes $\left(-5.2\right.$ to $\left.-1.4 \log \mathrm{cd} \mathrm{s} / \mathrm{m}^{2}\right)$, and up to $20 \mathrm{~s}$ for the brightest flashes $(-0.8$ to $0 \log \mathrm{cd} \mathrm{s} / \mathrm{m}^{2}$ ). ERG records were amplified and band-pass filtered (1-1000 Hz, without notch filtering) using a DAM50 data acquisition board (World Precision Instruments, Aston, UK). A PowerLab system (AD Instruments, Oxfordshire, UK) was used for the administration of stimuli and data acquisition ( $4 \mathrm{kHz}$ ). The a-wave amplitude was measured from the baseline to the trough of the a-wave. The b-wave amplitude measurement was taken from the trough of the a-wave to the peak of the b-wave.

\section{Optomotor test}

To evaluate visual parameters, the spatial frequency threshold was assessed for awake, freely moving mice at P30. Optomotor responses to horizontally drifting, vertically oriented gratings were observed and scored using the Argos system (Instead, Elche, Spain). The spatial frequency threshold of the behavior was determined as the maximum spatial frequency at maximum contrast that still induced smooth head tracking movements. For testing, a mouse was placed on a platform in the center of a chamber with walls made of computer monitors. Sinusoidal gratings were projected for $5 \mathrm{~s}$ on all four monitors as a cylinder centered on the head, and the virtual cylinder displayed on the monitors was rotated in both horizontal directions. The mouse was imaged via an overhead video camera for a trained observer to score smooth head turns in response to the rotating gratings. The initial spatial and temporal frequencies of the gratings were 0.088 cyc/deg and $0.8 \mathrm{~Hz}$, respectively. Each increasing spatial frequency was tested 10 consecutive times, and the observed responses were considered positive if tracking movements of the head corresponded to that of the drum rotation in at least $80 \%$ of the stimuli tested. We observed these tracking responses as being robust at middle spatial frequencies and diminishing until they were extinguished at threshold.

\section{Immunohistochemistry}

Histological studies of the retinas were performed at P30 following previously well established procedures [15]. Briefly, the animals were sacrificed in the morning. After marking the dorsal margin of the limbus with a suture, eyes were enucleated and fixed in $4 \%(\mathrm{w} / \mathrm{v})$ paraformaldehyde during $1 \mathrm{~h}$ at room temperature. After being washed in $0.1 \mathrm{M}$ phosphate buffer pH 7.4 (PB), eyes were cryoprotected 


\section{Cellular Physiology Cell Physiol Biochem 2020;54:142-159

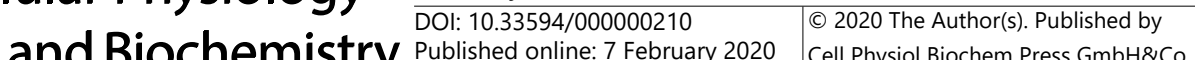 \\ Published online: 7 February 2020 Cell Physiol Biochem Press GmbH\&Co. KG \\ Campello et al.: Novel Nrf2 Inducer ITH12674 Slows Retinal Degeneration}

sequentially in 15, 20 and $30 \%(\mathrm{w} / \mathrm{v}$ ) sucrose. The cornea, lens and vitreous body were removed, and then the eyecups were embedded in Tissue-Tek OCT (Sakura Finetek, Zoeterwouden, Netherlands) and frozen in liquid $\mathrm{N}_{2}$. Sixteen-micrometer-thick sections were obtained at $-25{ }^{\circ} \mathrm{C}$ in a cryostat, mounted on slides (Superfrost Plus; Menzel GmbH and Co. KG, Braunschweig, Germany) and stored at $-20{ }^{\circ} \mathrm{C}$. Before further use, slides were thawed, washed 3 times with $\mathrm{PB}$ and incubated with blocking solution $(10 \%(\mathrm{v} / \mathrm{v})$ donkey serum and $0.5 \%(\mathrm{v} / \mathrm{v})$ triton X-100 in PB) for $1 \mathrm{~h}$. Sections were subjected to single or double immunostaining with combinations of antibodies at different dilutions in PB with $0.5 \%$ Triton X-100 overnight at room temperature.

Primary antibodies used in this work have been used extensively in previous studies and have been well characterized regarding cell type specificity. Sections were first incubated with one or more of the following primary antibodies: Rabbit anti-cone arrestin (1:500; Chemicon-Millipore, Temecula, CA, USA), rabbit anti-rhodopsin (1:500; Chemicon-Millipore), mouse anti-bassoon (1:1000; Enzo Life Sciences, Plymouth Meeting, PA, USA), rabbit anti-calbindin (1:500; Swant, Bellinzona, Switzerland), mouse anti-C-terminal binding protein-2 (CtBP2) (1:1000; BD Biosciences, San Diego, CA, USA) and/or guinea pig anti-vesicular glutamate transporter 1 (VGluT1) (1:1000; Chemicon-Millipore), mouse anti-MHC class II RT1B (clone OX-6, 1:200; AbD Serotec, Kidlington, UK), rabbit anti-Iba1 (1:1000; Wako Chemicals, Richmond, VA, USA), rabbit anti-GFAP (1:50; Dako, Santa Clara, CA, USA). Next day retinal sections were subsequently washed in PB and incubated with the corresponding mixture of the following secondary antibodies at a 1:100 dilution for 1 hour at RT: AlexaFluor 488 donkey anti-rabbit IgG, AlexaFluor 555 donkey anti-mouse IgG, and AlexaFluor 633 donkey anti-guinea pig IgG (Invitrogen, Carlsbad, CA, USA). TO-PRO 3-iodide (Invitrogen) was added at $1 \mu \mathrm{M}$ with the secondary antibodies in order to visualize nuclei. Images were taken using a Leica TCS SP2 confocal laser-scanning microscope (Leica Microsystems). Images were processed in parallel with Adobe Photoshop 10 software (Adobe Systems Inc., San Jose, CA, USA). Measurements of the thickness of the retinal layers were performed using the NIH ImageJ software developed by Wayne Rasband (National Institutes of Health, Bethesda, MD, United States).

\section{Quantification of photoreceptor rows}

To study retinal degeneration, we quantified photoreceptor rows, using the nuclear marker TO-PRO 3 , in at least three non-consecutive retinal sections of each animal. Quantifications were performed at distances of $0.5,1.5,2.5$ and $3.5 \mathrm{~mm}$ from the optic nerve, toward both the temporal and nasal ora serratas. An average value of photoreceptor rows was calculated for each animal.

\section{Flow cytometry}

The immune system-related cell populations in the retina were analyzed using flow cytometry. A retinal cell suspension was labeled with a cocktail of five antibodies acquired from e-Bioscience (San Diego, CA, USA): anti-CD11b-PE (Clone M/170), anti-CD45-FITC (Clone 30-F11), anti-CD11c-PerCpCy5.5 (Clone N418), anti-MHC class II (I-A/I-E)-PECy7 (Clone M5/114.15.2), anti-CD169-eFluor 660 (Clone SER-4). After discarding debris events, the CD45 positive cell subpopulations were analyzed for their immunoreactivity against MHC class II, the dendritic cell marker CD11c and the sialoadhesin (CD169) antibodies. Each mouse retina was analyzed individually. Data were acquired on a LSR Fortessa cytometer (BD Biosciences) and analyzed using FCS 6 Flow Cytometry Software (De Novo, Los Angeles, CA, USA).

\section{Western blotting}

The expression of proteins associated with inflammation, cell viability and cell death was tested by Western blotting. Protein extracts were obtained and resolved by denaturing sodium dodecyl sulfatepolyacrylamide gel electrophoresis (SDS-PAGE). Briefly, retinas were isolated and proteins were extracted using RIPA buffer (Sigma Aldrich, Germany) containing protease (complete EDTA-free; Roche, Mannheim, Germany) and phosphatase (PhoStop; Roche) inhibitor cocktails. After incubation on ice for 30 min, debris was pelleted by a 10 -min centrifugation $(10000 \mathrm{xg})$ at $4{ }^{\circ} \mathrm{C}$ and protein concentration in the supernatants was quantified with the Bio-Rad protein assay (Bio-Rad, Philadelphia, PA, USA), using bovine serum albumin as standard. $20 \mu \mathrm{g}$ of protein were diluted in Laemmli sample buffer (4\% SDS, $100 \mathrm{mM}$ dithiothreitol, 20\% glycerol, $0.004 \%$ bromophenol blue, $125 \mathrm{mM}$ Tris- $\mathrm{HCl}, \mathrm{pH}$ 6.8) and resolved on 5-12\% SDS-PAGE gels. Proteins were transferred onto PVDF membranes (Roche) and the blots were blocked with $2.5 \%$ (w/v) non-fat dry milk in Tris-buffered saline/0.1\% Tween-20 (TBS/T, pH 7.6), for $1 \mathrm{~h}$ at room temperature. 


\section{Cellular Physiology Cell Physiol Biochem 2020;54:142-159

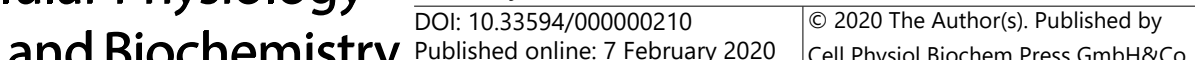 \\ Published online: 7 February 2020 Cell Physiol Biochem Press GmbH\&Co. KG \\ Campello et al.: Novel Nrf2 Inducer ITH12674 Slows Retinal Degeneration}

Membranes were incubated at $4{ }^{\circ} \mathrm{C}$ overnight, with the appropriate dilution of primary antibody: mouse anti-Rhodopsin (Millipore), rabbit anti-Atg12-Atg5 (Abcam, Cambridge, United Kingdom), rabbit anti-p38 MAPK (Cell Signaling Technology, Danver, MA, USA), rabbit anti-TNF- $\alpha$ (Millipore), rabbit anti-p65 NF- $\kappa B$ (Santa Cruz Biotechnology, Dallas, TX, USA), rabbit anti-Bcl-2 (Santa Cruz Biotechnology, Dallas, TX, USA), and mouse anti- $\beta$-actin (Sigma Aldrich). After three 5-min washes with TBS/T, blots were incubated with the corresponding peroxidase-conjugated secondary antibody (dilution 1:1000, Thermo Fisher Scientific, Waltham, MA, USA) for $1 \mathrm{~h}$ at room temperature. Blots were then washed again three times with TBS/T, rinsed briefly with phosphate buffer saline, and developed with the Lumi-light western blotting substrate (Roche). Detection of $\beta$-actin ( $\beta$-actin 1:5000) was used as housekeeping protein.

\section{Blood-brain barrier permeation}

Prediction of the brain penetration was evaluated using a PAMPA-BBB assay [16], in which a porcine brain lipid was used as an artificial membrane (PBL, 141101 Avanti Polar Lipids). The donor plate was a 96-well filter plate with hydrophobic PVDF membrane (pore size $0.45 \mu \mathrm{m}$, sterile, MultiScreen MAIPS4510) and the acceptor plate was a 96-well collection plate (MultiScreen MAMCS9610), both from EDM Millipore Sigma. 96-well UV plates with a flat bottom were used for UV measurements (655801, Greiner Bio-One). Test compounds (10 mM, DMSO stock solution) were diluted with PBS buffer ( $\mathrm{pH}=7.4)$ to generate a final concentration of $100 \mu \mathrm{M}$ (1\% DMSO). The acceptor plate was filled with $180 \mu \mathrm{L}$ of $10 \mathrm{mM}$ PBS (1\% DMSO). The donor plate was first coated with $4 \mu \mathrm{L}$ of PBL $(20 \mathrm{mg} / \mathrm{mL}$ in dodecane). Then $180 \mu \mathrm{L}$ of test compound $(100 \mu \mathrm{M})$ was subsequently added to the donor plate. The donor plate was then carefully placed on top of the acceptor plate to make a "sandwich", which was left undisturbed at $25^{\circ} \mathrm{C}$ for $4 \mathrm{~h}$. During this time, compounds diffuse from the donor plate to the acceptor plate. After incubation, UV plate reader (SPECtROStar Nano, BMG Labtech) determined the concentration of compounds and commercial drugs in the acceptor and the donor wells. Every sample was analyzed at three to five wavelengths, in two wells, and in two independent runs. Results are given as mean \pm standard deviation (SD), and the average of the two runs is reported. Four quality control compounds of known BBB permeability were included in each experiment to validate the analysis set. Compounds were classified attending to the following classification ranges: CNS + (high BBB permeation predicted) when $\mathrm{P}_{e}\left(10^{-6} \mathrm{~cm} \mathrm{~s}^{-1}\right)>4.0$; CNS - (low BBB permeation predicted) when $\mathrm{P}_{e}\left(10^{-6} \mathrm{~cm}\right.$ $\left.\mathrm{s}^{-1}\right)</ 2.0$; CNS +/- (BBB permeation uncertain) when $\mathrm{P}_{e}\left(10^{-6} \mathrm{~cm} \mathrm{~s}^{-1}\right)$ from 4.0 to 2.0.

\section{Statistical analysis}

Normal distribution and homogeneous variance were found for the variables: ERG amplitude and number of photoreceptor rows, so that a two-way ANOVA was applied to assess significant effect of treatment and measurement conditions. Post hoc pairwise comparisons using Bonferroni's test were carried out when a 0.05 level of significance was obtained. Student's t-test were conducted to evaluate visual acuity and variables from Western blotting, quantification of synaptic ribbons and flow cytometry. Data are reported as the mean \pm standard error of the mean or standard deviation, as indicated. Values of $\mathrm{P}<$ 0.05 were considered to be statistically significant. All statistical analyses were performed using SPSS 22.0 software (Statistical Package for Social Sciences, Chicago, IL, USA).

\section{Results}

ITH12674 increases visual responses in rd10 mice

In order to evaluate the effect of ITH12674 on the functional activity of rd10 mice retinas, scotopic flash-induced ERG responses were recorded in animals treated with ITH12674 (1 or $10 \mathrm{mg} / \mathrm{kg}$ ) or with vehicle. ERG recordings from normal C57BL/6J mice served as reference. rd10 mice treated with $10 \mathrm{mg} / \mathrm{kg}$ ITH12674 showed scotopic single-flash ERG responses higher than those obtained in mice treated with $1 \mathrm{mg} / \mathrm{kg}$ ITH12674 or vehicle (Fig. 2A). Mean values of a- and b-wave amplitudes from ITH12674 $10 \mathrm{mg} / \mathrm{kg}$-treated mice were significantly greater (respectively, $20 \%$ and $28 \%$ of increase at the higher stimulus intensities) than those measured in control ones (ANOVA, Bonferroni's test) (Fig. 2C). No differences were observed between animals treated with doses of $1 \mathrm{mg} / \mathrm{kg}$ and untreated mice (Fig. 2C). Scotopic Doubleflash protocol showed ERG responses slightly increased in ITH12674 $10 \mathrm{mg} / \mathrm{kg}$-treated mice 


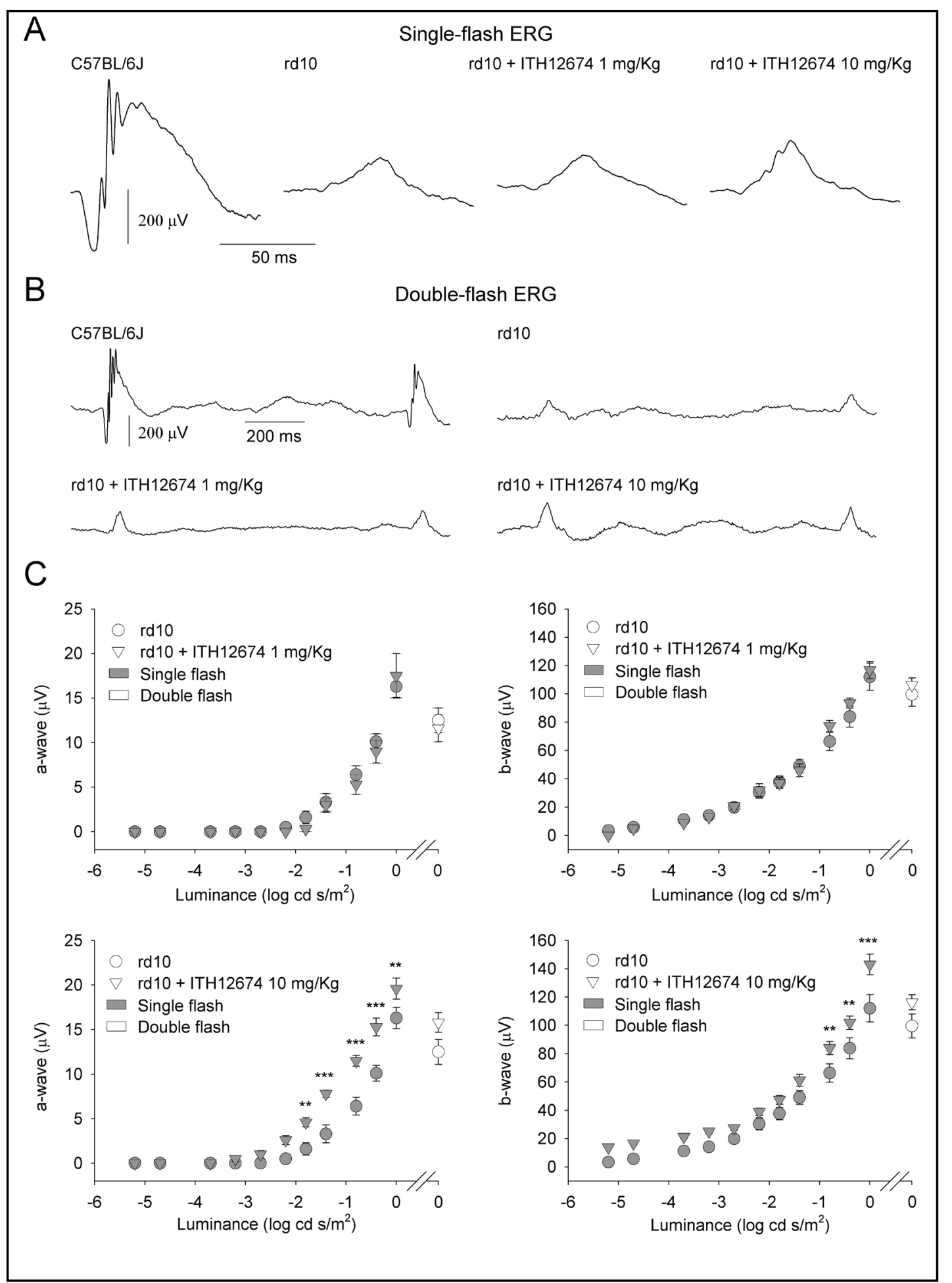

Fig. 2. Effect of ITH12674 on retinal responsiveness. (A, B) Dark-adapted intensity responses to single(A) and double-flash (B) ERG stimuli at $0 \log \mathrm{cd} \mathrm{s} / \mathrm{m}^{2}$ from a normal mouse (C57BL/6J), a non-treated dystrophic mouse (rd10) and ITH12674-treated rd10 mice (rd10 + ITH12674) at P30. (C) Luminanceresponse curves of rd10 mice non-treated ( $n=7$, circles) and treated with ITH12674 (inverted triangles) at a dose of $1 \mathrm{mg} / \mathrm{kg}(\mathrm{n}=4$, upper graphs) or $10 \mathrm{mg} / \mathrm{Kg}$ ( $\mathrm{n}=15$, lower graphs) from P16 to P30. Each graph includes measurements from both mixed (grey symbols) and cone-driven (white symbols) responses. Data are mean values $\pm \mathrm{SEM} .{ }^{*} \mathrm{P}<0.01,{ }^{* *} \mathrm{P}<0.005,{ }^{* * *} \mathrm{P}<0.001$. 
as compared to non-treated mice (Fig. 2B), with a relative increment in the average amplitude of the a- and b-waves (20 and $28 \%$ higher, respectively), but differences were no significant (ANOVA, Bonferroni's test). Visual acuity was analyzed in the same animals by the optomotor test. Mice treated with ITH12674 at $10 \mathrm{mg} / \mathrm{kg}$ showed an increased visual acuity $(35.6 \%)$ with respect to the untreated mice, while no significant differences were found between mice treated with ITH12674 at $1 \mathrm{mg} / \mathrm{kg}$ and control mice (Fig. 3).

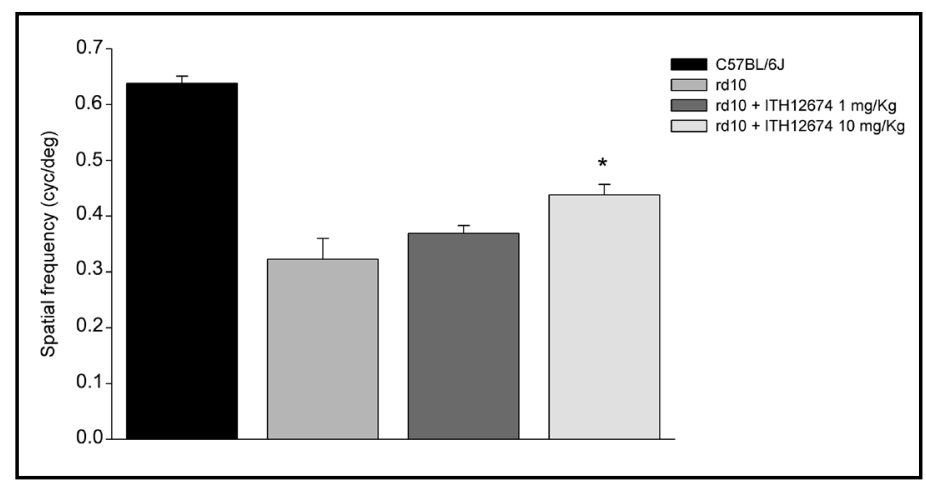

Fig. 3. Effect of ITH12674 on visual acuity. Spatial frequency threshold (in cycles per degree) in an optomotor test in C57BL/6 $(\mathrm{n}=6)$, non-treated $(\mathrm{n}=7)$ and treated rd10 mice with ITH12674 at a dose of $1 \mathrm{mg} / \mathrm{kg}(\mathrm{n}=4)$ and $10 \mathrm{mg} / \mathrm{Kg}(\mathrm{n}=15)$. Data are mean \pm SEM. $* \mathrm{P}<0.01$.

\section{ITH12674 preserves photoreceptor morphology in rd10 mice}

To evaluate whether ITH12674 was able to preserve the morphology of photoreceptors in the degenerating retina, we analyzed retinal sections using antibodies against cone arrestin, a cone-specific marker [14] (Fig. 4A-C) and rhodopsin, specific for rods (Fig. 4D-F) in rd10 mice (Fig. 4B, C, E, F) and C57BL/6J mice (Fig. 4A, D). In non-treated rd10 mice (Fig. 4B), cones showed a very small size, with short and swollen outer and inner segments. In these animals, axons were reduced and, in some of them, pedicles emerged directly from the cone cell bodies. In contrast, cone photoreceptors in animals treated with $10 \mathrm{mg} / \mathrm{kg}$ ITH12674 (Fig. 4C) display better preserved morphology with longer outer and inner segments as well as longer axons, and better conserved pedicles, showing the typical cone shape compared to untreated animals. No differences in retinal morphology were observed between animals treated with $1 \mathrm{mg} / \mathrm{kg}$ and control ones. Also, rod morphology was better preserved in ITH12674-treated (10 mg/kg) rd10 mice (Fig. 4F) compared to non-treated rd10 mice (Fig. 4E). In ITH12674-treated animals rod outer segments appeared longer compared to those in non-treated animals. Indeed, in non-treated animals, rhodopsin immunoreactivity appears dislocated around the cytoplasm (Fig. 4F).

\section{ITH12674 decreases photoreceptor loss in rd10 mice}

Because the progression of RP varies across the retina, we quantified the number of photoreceptor rows (Fig. 5A) in different areas of the retina, from the temporal to the nasal zones, using the nuclear dye TO-PRO-3 in vertical sections of P30 retinas. Although no statistically significant differences were found between treated and untreated animals in any of the areas analyzed, the average number of photoreceptor rows throughout the whole analyzed area resulted significantly higher in animals treated with 10mg/kg ITH12674 compared to untreated animals (ANOVA, Bonferroni's test, $\mathrm{p}<0.05$ ) (Fig. 5B). To assess the protective action of ITH12674 on the photoreceptors, we quantified by Western blot the expression of rhodopsin in the retinas of treated and untreated rd10 mice (Fig. 5C). A statistically significant increased expression of rhodopsin was confirmed in rd10 mice treated with $10 \mathrm{mg} / \mathrm{kg}$ ITH12674 (increased by 47.2 1 10,7\%) compared to untreated mice (Student's t-test, $\mathrm{p}<0.05$ ) (Fig. 5D). 




Fig. 4. Effect of ITH12674 treatment $(10 \mathrm{mg} / \mathrm{kg})$ on photoreceptors of rd10 mice. (A-C) Vertical sections of retinas from C57BL/6J (A), non-treated rd10 (B) and ITH12674-treated mice (age P30) labeled for cone arrestin (cone cells, green), and TO-PRO 3 (nuclei, blue). Arrowheads point to conserved axons and vertical arrows point to conserved cone pedicles. (D-F) Vertical sections of retinas from C57BL/6J (D), non-treated rd10 (E) and ITH12674-treated mice (F) (age P30) labeled for rhodopsin (rod cells, red), and TO-PRO 3 (nuclei, blue). Scale bar: $20 \mu \mathrm{m}$. 


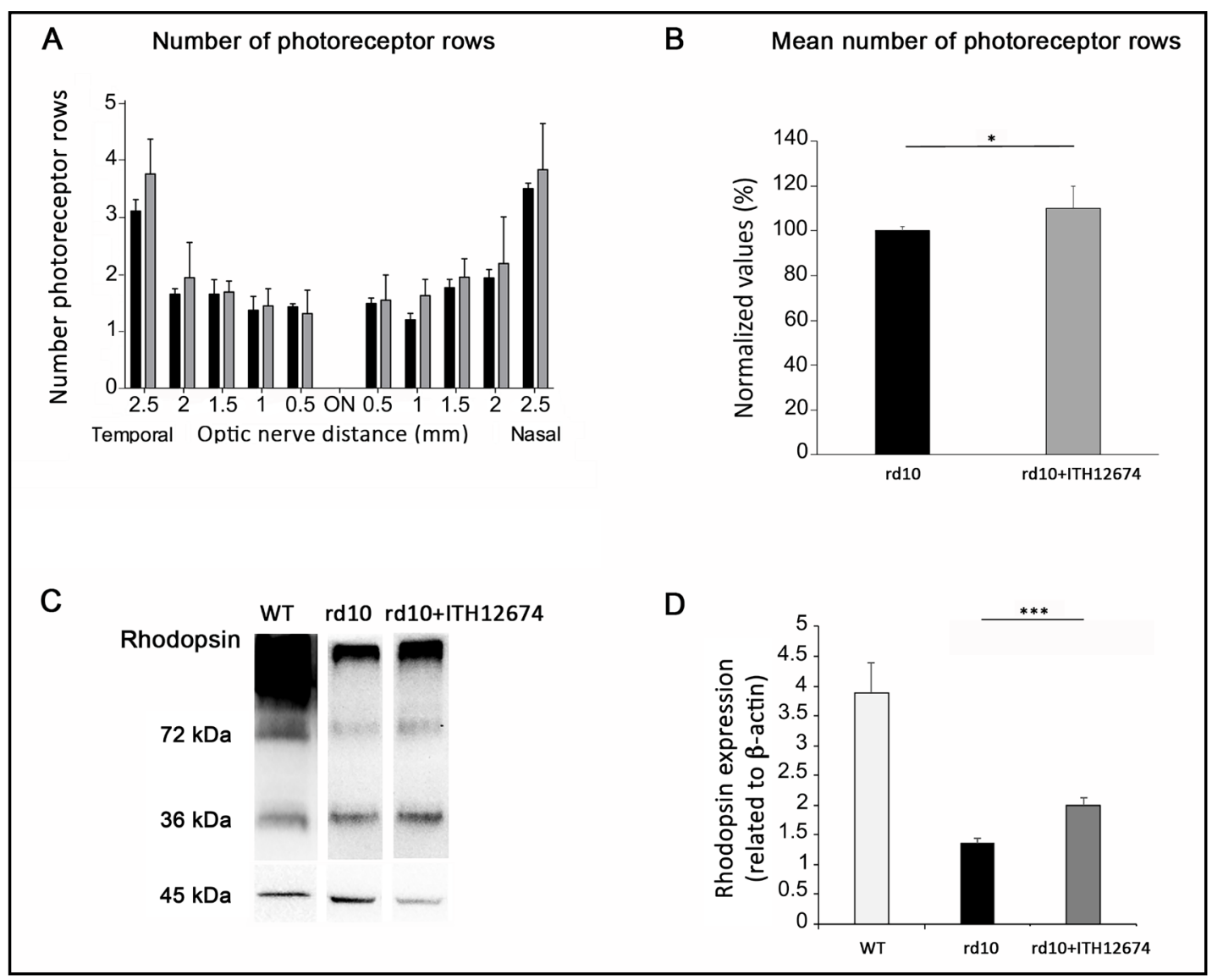

Fig. 5. Effect of ITH12674 treatment $(10 \mathrm{mg} / \mathrm{kg})$ on photoreceptors of rd10 mice. (A) Quantification of photoreceptor rows along central sections of the retina in both, non-treated and treated retinas (at least $n=3$ in each condition). Error bars represent the SEM. (B) Normalized mean values of photoreceptor rows in both, non-treated and treated retinas. (C) Image of representative Western blots showing rhodopsin levels in non-treated and ITH12674-treated rd10 mice. Rhodopsin expression in a C57BL/6J mice (WT) is shown as reference. Immunoreactive bands at $36 \mathrm{kDa}$ belonging to rhodopsin monomers can be observed. Higher bands correspond to rhodopsin dimers and multimers. All bands were quantified in each lane. Western blots were performed by triplicates. (D) Bar graph shows the quantification of rhodopsin levels analyzed by Western blotting in treated and non-treated rd10 animals, 3 animals in each condition. Expression levels in C57BL/6J mice (WT) are shown as reference. Data are normalized to the expression of $\beta$-actin. ${ }^{*} \mathrm{P}<0.01$.

\section{ITH12674 maintains photoreceptor connectivity in rd10 mice}

In order to study synaptic connectivity between photoreceptors and horizontal cells, we immunolabeled retinal sections with antibodies against (i) the vesicular glutamate transporter type 1 (VGluT1), (ii) the C-terminal binding protein 2 (CtBP2) and (iii) calbindin. The VGluT1 transports glutamate into synaptic vesicles, and was used to visualize cone and rod axon terminals [17]. Synaptic ribbons in the photoreceptor axon terminals were identified with CtBP2 antibody, which recognizes the domain B of RIBEYE, a structural protein of synaptic ribbons [18-20]. Horizontal cell processes were visualized with anticalbindin antibody [21, 22] (Fig. 6). Immunolabeling against calbindin in ITH12674 treated animals $(10 \mathrm{mg} / \mathrm{kg})$ showed horizontal cells with longer and more horizontal dendritic tips (Fig. 6B) compared to untreated animals (Fig. 6A). Moreover, ITH12674-treated animals displayed a higher number of synaptic ribbons revealed by the density of CtBP2 spots showing the typical horse-shoes morphology (Fig. 6D) compared to untreated animals (Fig. 6C). The number of synaptic ribbons in outer plexiform layer (OPL) was significantly higher in ITH12674-treated animals $(378.90 \pm 31.58$ vs. 276.43 \pm 63.84 synaptic ribbons per 


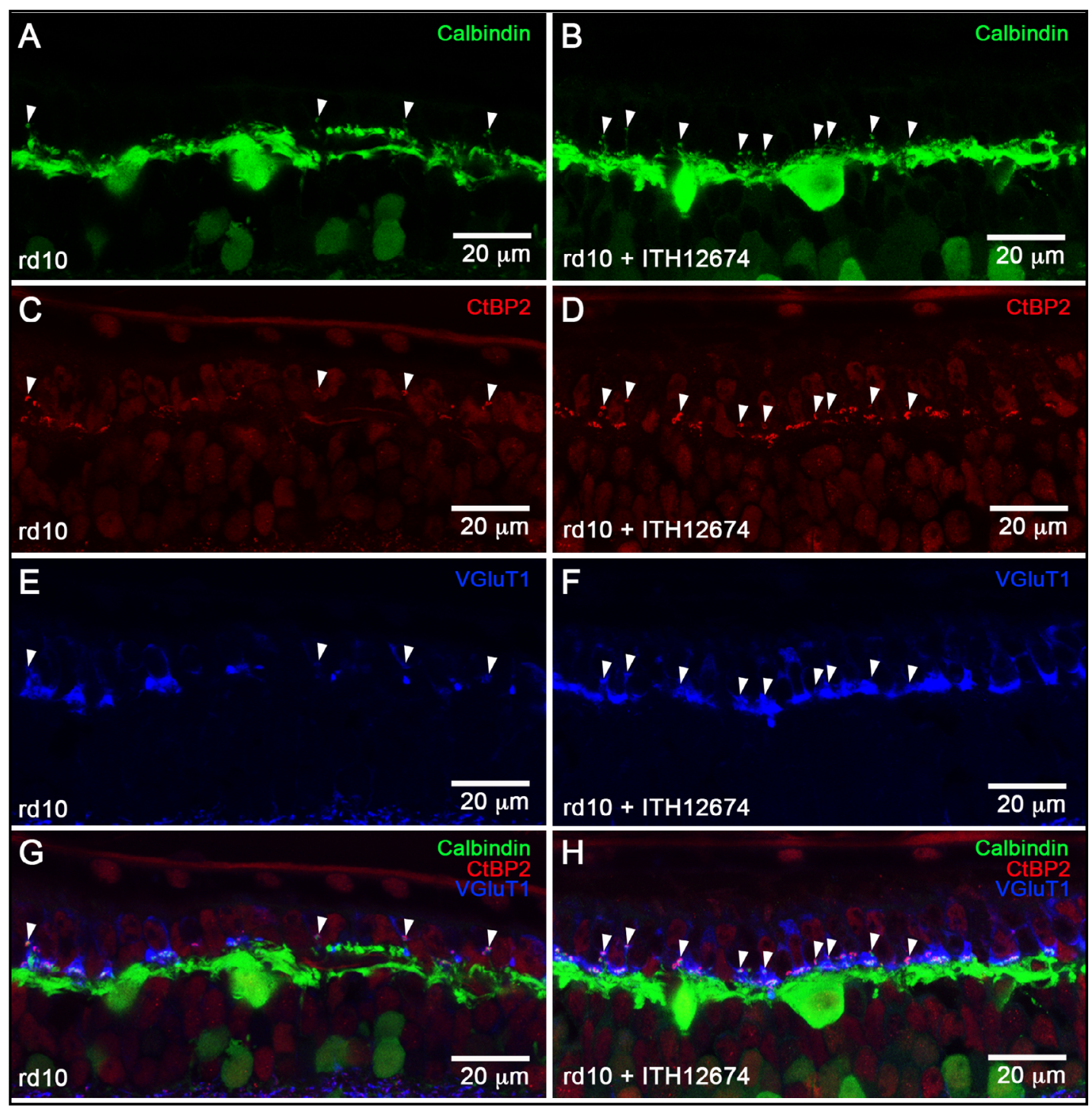

Fig. 6. Effect of ITH12674 on photoreceptor connectivity. (A-H) Representative vertical central retinal sections of rd10 mice (A,C,E,G) and ITH12674-treated $(10 \mathrm{mg} / \mathrm{Kg}$ ) rd10 mice (B,D,F,H) (age P30) labeled for calbindin (green; A,B), CtBP2 (red; C,D), VGluT1 (blue; E,F) and merged images (G,H). In ITH12674treated animals, immunolabeling showed horizontal cells with longer and more horizontal dendritic tips (Calbindin), a higher number of ribbon synapsis (higher density of CtBP2 spots showing the typical horseshoes morphology) and a continuous OPL layer with still functional photoreceptor axon-terminals (VGluT1 staining). The merged image shows higher density of complete synaptic connections ( $\mathrm{H}$, arrowheads).

$\mathrm{mm}$ in ITH12674-treated and non-treated rd10 mice respectively, Student's t-test, $\mathrm{p}<0.05$ ). VGluT1 staining showed a continuous OPL in ITH12674 treated animals (Fig. 6F) indicating the presence of still functional photoreceptor axon-terminals. In contrast, in untreated animals, only some photoreceptor axon-terminals were stained with VGluT1 (Fig. 6E). The merge of the three markers mentioned before revealed a higher density of complete synaptic connections, containing all elements, the glutamate transporter, the synaptic ribbon and the horizontal dendritic tip between photoreceptor and horizontal cells, in ITH12674 treated animals (Fig. 6H, arrowheads). In contrast, in untreated animals it was difficult to find the three markers in the same synaptic contact (Fig. 6G, arrowheads). 


\section{Cellular Physiology Cell Physiol Biochem 2020;54:142-159

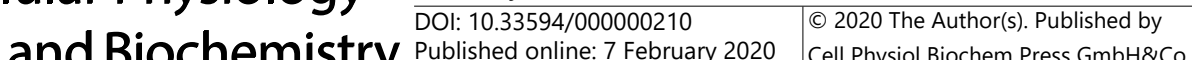 \\ \begin{tabular}{ll} 
Published online: 7 February 2020 Cell Physiol Biochem Press GmbH\&Co. KG \\
\hline
\end{tabular}}

ITH12674 reduces the oxidative stress and inflammatory state of the degenerative rd10 mice retina

In order to evaluate if ITH12674 was able to reduce the microgliosis and the inflammatory state of rd10 mouse retinas, as a first approximation we searched for morphological changes in microglia and Müller cells by immunolabeling retinal sections with antibodies against microglia (Iba1, MHC class II) and activated Müller cells (GFAP), altogether with the nuclear staining marker TO-PRO 3. Morphologically, no differences were observed in microglial cells between ITH12674-treated (10 mg/Kg) (Fig. 7B) and non-treated rd10 mice (Fig. 7A) or in Müller cells in treated (Fig. 7D) and control mice (Fig. 7C).

As changes in the inflammation markers are not necessarily always accompanied by changes in cellular morphology, at least in this state of the degenerative process, we further analyzed the oxidative stress and activated inflammatory signaling pathways in treated and non-treated animals, the expression of anti apoptotic (Bcl-2), autophagic (Atg12-Atg5, p38 MAPK) and inflammatory (TNF- $\alpha, N F-\kappa B$ ) specific biomarkers was analyzed by Western blotting (Fig. 7E, F). Analysis showed that ITH12674 at a dose of $10 \mathrm{mg} / \mathrm{kg}$ reduced the protein levels of TNF- $\alpha$ by $50 \%$ and NF- $\kappa$ B by $60 \%$ compared to their untreated counterparts. On the other hand, the pro-survival biomarkers Atg12-Atg5 and p38 MAPK were up-regulated after ITH12674 treatment; p38 MAPK protein levels increased by $40 \%$ and the increase of Atg12-Atg5 was around 300\%. Differences between Bcl-2 expression values did not reach significance between the two groups.

We also analyzed immune-related cell populations in the degenerating retinas by flow cytometry, evaluating the immunoreactivity against CD11b, CD45, CD11c, MHC class II and CD169 antibodies (Fig. 8). Both, ITH12674-treated and non-treated rd10 mice showed similar mean intensity fluorescence values for CD11b $(11015 \pm 373$ and $10502 \pm 373$ respectively). In ITH12674-treated $\mathrm{rd} 10$ mice $(10 \mathrm{mg} / \mathrm{kg})$, the cell population simultaneously positive for CD45 and CD11c was lower than that observed in non-treated mice (Fig. 8A-D): CD 45 ${ }^{+}$ population with intermediate CD11c fluorescence values was 34\% reduced in ITH12674treated rd10 mice (Student's t-test, $\mathrm{p}<0.0001$ ), and the population with the phenotype $\mathrm{CD}^{2} 5^{+} \mathrm{CD} 11 \mathrm{c}^{\text {high }} \mathrm{MHC}$ class II ${ }^{\text {high }}$ was 74\% lower in ITH12674-treated rd10 mice (Student's t-test, $\mathrm{p}<0.0001$ ). Conversely, the $\mathrm{CD}^{2} 5^{+} \mathrm{CD} 11 \mathrm{c}^{-} \mathrm{MHC}$ class II- population was $84 \%$ higher in non-treated rd10 mice (Student's t-test, $\mathrm{p}<0.0001$ ). Moreover, ITH12674-treated rd10 mice showed a decrease in $\mathrm{CD} 45^{+} \mathrm{CD} 169^{+}$population compared with non-treated animals (5.36 \pm 1.69 vs $11.75 \pm 3.09$ respectively) (Student's t-test, $\mathrm{p}<0.0001$ ) (Fig. 8E, F).

Altogether, these results point to an effect of ITH12674 reducing the oxidative stress and the inflammatory state of the degenerating retina.

ITH12674 is highly permeable in a prediction assay of the brain penetration

We performed a prediction of the brain penetration using a PAMPA-BBB assay (Table 1). Permeability value for ITH12674 was $21.8 \pm 1.2 \times 10^{-6} \mathrm{~cm} \mathrm{~s}^{-1}$, as other highly permeable commercial drugs. 


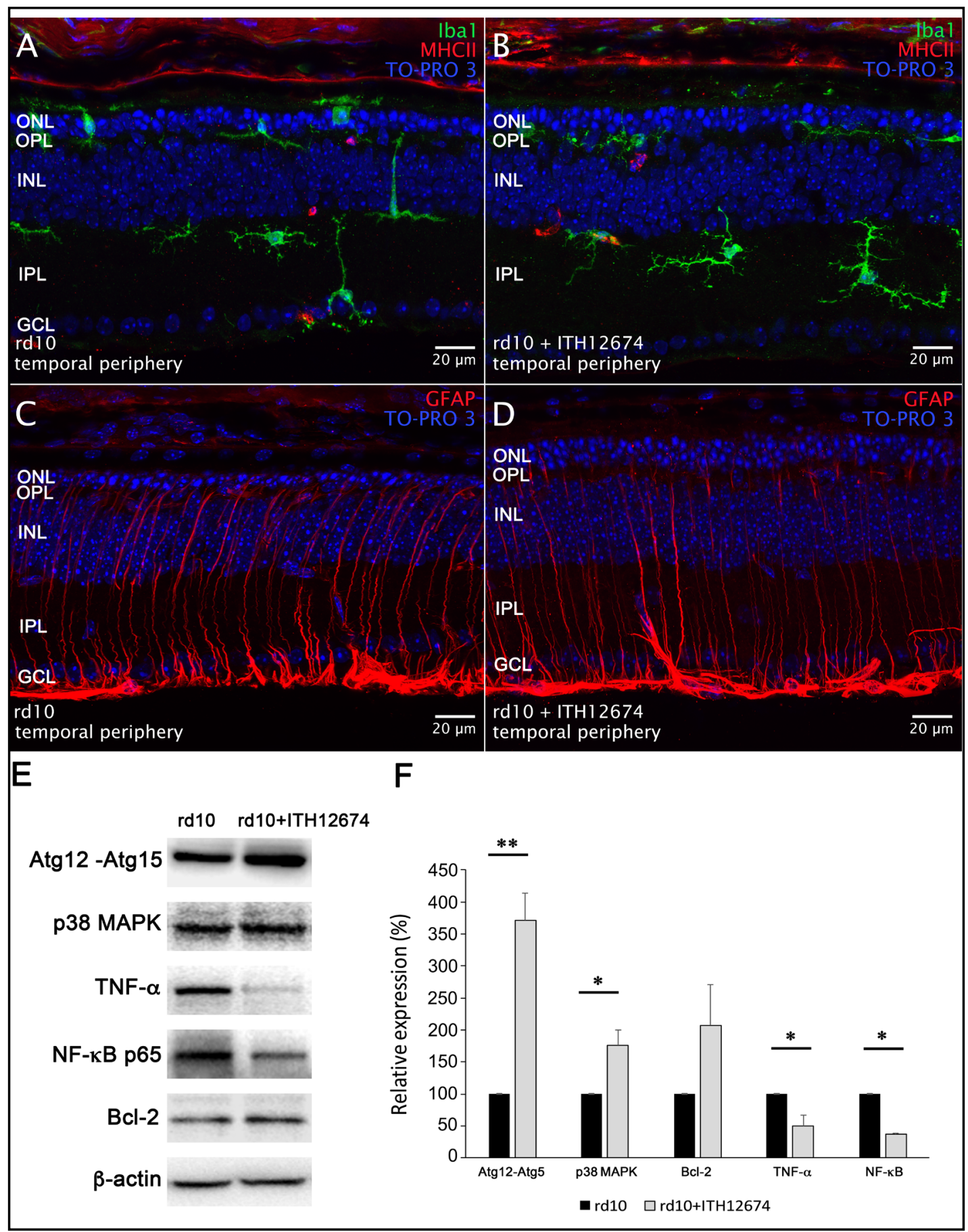

Fig. 7. Effect of ITH12674 on the oxidative stress and inflammatory state of the retina. (A-D) Representative vertical retinal sections of non-treated $(A, C)$ and ITH12674-treated rd10 mice (10 mg/Kg) (B, D) (age P30) labeled for Iba1 (microglial cells, green), MHC class II (activated microglial cells, red) and GFAP (Müller cells, red). Nuclei were stained with TO-PRO 3 (blue). ONL: outer nuclear layer; OPL: outer plexiform layer; INL: inner nuclear layer; IPL: inner plexiform layer; GCL: ganglion cell layer. Scale bar $20 \mu \mathrm{m}$. (E) Representative images of Western blots showing the relative expression levels of Atg12-Atg5, p38 MAPK, TNF- $\alpha, N F-\kappa B$, Bcl-2 and $\beta$-actin in non-treated rd10 and ITH12674-treated animals. Western blots were performed by triplicates. (F) Bar graph shows the quantification of the expression levels obtained from 3 independent experiments. ${ }^{*} \mathrm{P}<0.01$. 


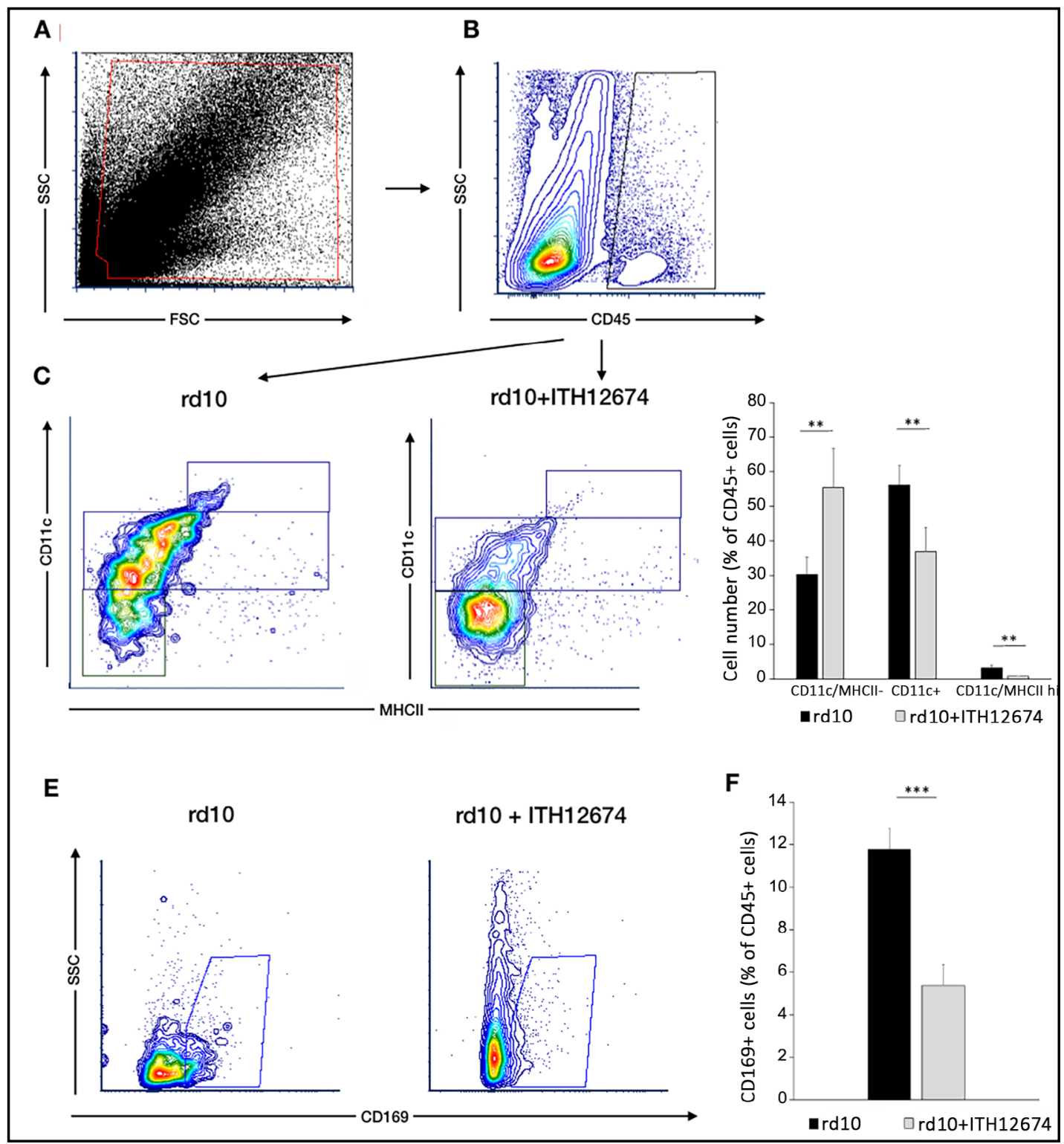

Fig. 8. Effect of ITH12674 on the immune cell populations in the retinas of rd10 mice. Whole retinal cells from non-treated and ITH12674-treated $(10 \mathrm{mg} / \mathrm{Kg}) \mathrm{rd} 10$ mice were labeled with a cocktail of five antibodies: PE-conjugated anti-CD11b, FITC-conjugated anti-CD45, PerCpCy5.5-conjugated anti-CD11c, PECy7-conjugated anti-MHC class II (I-A/I-E), and eFluor 660-conjugated anti-CD169, and analyzed by flow cytometry. (A) Dot plot representing SSC against FSC of a whole mouse retina. (B) The CD45-positive cells were gated. (C) Double plots presenting CD11c and MHC class II immunofluorescence of CD $45^{+}$cells. Image shows data from a single representative experiment in each condition. (D) Bar graph showing different phenotype populations (\% of CD45 positive cells) labeled with anti-CD11c and MHC class II antibodies from non-treated and ITH12674-treated mice. (E) Contour plots representing SSC against CD169 expression of $\mathrm{CD} 45^{+}$gated cells. Image shows data from a single representative experiment in each case. (F) The graph shows mean values of CD169 positive population ( $\%$ of CD45 positive population) in each condition. Each dot plot is representative of a minimum of four independent replicates. Data are mean values $\pm \mathrm{SEM}$. ${ }^{* *} \mathrm{P}<0.001$. 
Table 1. Permeability $\left(\mathrm{P}_{\mathrm{e}} 10^{-6} \mathrm{~cm} \mathrm{~s}^{-1}\right)$ in the PAMPA-BBB Assay for commercial drugs (used in the experiment validation) and ITH12674, with their predictive penetration in the CNS. ${ }^{a}[16]$. ${ }^{b}$ Data are the mean \pm SD of 2 independent experiments

\begin{tabular}{lccc}
\hline Compound & Bibl $^{\mathrm{a}}$ & $\left(\mathrm{Pe} 10^{-6} \mathrm{~cm} \mathrm{~s}^{-1}\right)^{\mathrm{b}}$ & Prediction \\
\hline Caffeine & 1.3 & $1.3 \pm 0.1$ & CNS - \\
Corticosterone & 5.1 & $6.1 \pm 0.3$ & CNS + \\
Hydrocortisone & 1.9 & $1.6 \pm 0.4$ & CNS - \\
Verapamil & 16.0 & $24.1 \pm 4.0$ & High permeability standard \\
ITH12674 & & $21.8 \pm 1.2$ & CNS+ \\
\hline
\end{tabular}

\section{Discussion}

Administration of novel Nrf2 inducer compound ITH12674 to rd10 mice for 2 weeks, mildly but significantly improved functional parameters such as ERG responses and visual acuity. This correlated with a better-preserved photoreceptors morphology as well as synaptic connectivity. Higher VGluT1 expression, a glutamate transporter involved in information transfer from photoreceptors to postsynaptic cells [23], supports such improved connectivity. These findings agree with those of previous studies showing that other Nrf2 inducers endowed with antioxidant and anti-inflammatory properties such as melatonin and sulforaphane, exhibited retinal neuroprotective effects in various rat and mouse models of retinal degeneration [11, 24-26]. As ITH12674 also displays neuroprotective properties in vitro, by inducing Nrf2 and antioxidant and anti-inflammatory pathways [12], ITH12674 could also exert its retinal neuroprotective properties through these and other signaling pathways.

ITH12674 augmented the expression of antiapoptotic Bcl-2 as well as Atg12-Atg5, a biomarker protein for autophagy. This protein has a main role in retinal degenerative diseases [27]; this is illustrated by an experiment in which the reduction of Atg12-Atg5 complex is associated to the development of AMD-like retinopathy [28]. As Nrf2 regulates different autophagy proteins [29], it seems plausible that the retina neuroprotective effects of ITH12674 are mediated by autophagy stimulation.

Another contributor in the retinal neuroprotective actions of ITH12674 is linked to its ability to enhance the p-p38 MAPK levels, the activated phosphorylated form of p38 MAPK, that is also increased by sulforaphane [30]. Consistent with this is the observation that the light-induced photoreceptor damage is accelerated by p38 MAPK inhibition, while its enhanced activity is protective [31]. In this line is an experiment showing that the carotenoid derivative crocetin increases p38 levels at the time it prevents retinal ischemic damage in mice [32].

MAP kinases function both upstream and downstream of TNF- $\alpha$ expression, a crucial pathway in inflammatory processes [33]. In this context, the augmentation of p38 MAPK by ITH12674 keeps pace with our observation that the compound elicited downregulation of TNF- $\alpha$ and NF- $\kappa B$ expression, consistent with its anti-apoptotic and anti-inflammatory effects. In line with this property is the protective role of melatonin in diabetic retinopathy, through the attenuation of inflammation by NF- $\kappa \mathrm{B}$ [34]. Also, it is accepted that microglial activation and the expression of chemokines and TNF- $\alpha$ play relevant roles in retinal degeneration [1]. Additionally, NF- $\kappa \mathrm{B}$ is activated in retinal degeneration of rd mice with concomitant microglial activation [35]. Furthermore, increased TNF- $\alpha$ expression is directly linked to increased retinal degeneration in the $\mathrm{P} 23 \mathrm{H}$ rat model [36].

Treatment with ITH12674 also evidenced a change in the phenotype of immunerelated cells. This is interesting as in retinal degeneration there is an activation of resident microglia, with concomitant recruitment of immune cells, and proliferation of monocytes that contribute to the tissue inflammatory state [1]. In the analysis of several cell biomarkers we found that ITH12674 produced a significant reduction in the CD11c and MHC class II positive cells. Integrin CD11c is highly expressed in injured and degenerating retinas [37-40]. 


\section{Cellular Physiology Cell Physiol Biochem 2020;54:142-159 \\ \begin{tabular}{ll|l} 
and Biochemistry $10.33594 / 000000210$ & O 2020 The Author(s). Published by \\
Published online: 7 February 2020 & Cell Physiol Biochem Press GmbH\&Co. KG
\end{tabular} \\ Campello et al.: Novel Nrf2 Inducer ITH12674 Slows Retinal Degeneration}

Also, MHC class II expression is upregulated in retinal injury and degeneration; its induction significantly correlates with disease severity [41-43]. ITH12674 also decreased the CD169 positive cell populations, related to infiltrating monocytes, macrophages, and dendritic cells but not microglia [44-48].

Some limitations of our study are related to the mild effects of ITH12674 on ERG and visual acuity in rd10 mice. This could be due to a short half-life of the compound; in spite of the fact it was administered twice a day for 2 weeks, a potential short half-life could limit a sustained residence time of the compound in retinal cells. Another limitation is the time window for the compound administration. This is due to the fact that, in neurodegenerative diseases the glia activation could be in M1 phase or proinflammatory or M2 phase or antiinflammatory [49].

However, there are also some positive aspects of our study. The most salient is the in vivo demonstration of the proof-of-concept that the in vitro neuroprotective, antioxidant, and anti-inflammatory properties of ITH12674 [12] are also reproduced in vivo, in a model of retinal degeneration, the RP rd10 mouse. This is stimulating in the context of our present work aimed at chemically optimizing the pharmacodynamics, pharmacokinetic, and safety profile of compound ITH12674.

\section{Conclusion}

In conclusion, novel Nrf2 inducer compound ITH12674 was previously found to exhibit neuroprotective effects on in vitro models of neurotoxicity. In the present study, we established the in vivo proof-of-concept of its retinal neuroprotection capabilities functionally, morphologically, and neurochemically, upon its chronic administration to rd10 mice, a model of RP. Such neuroprotection properties are linked to its ability to reduce the expression of various inflammatory markers, by attenuating microglia activation.

\section{Acknowledgements}

\section{Funding sources}

This work was supported by grants from Bayer (Grats4Targets), from the Spanish Ministry of Economy and Competitiveness (MINECO-FEDER BFU2015-67139-R), Spanish Ministry of Education (FPU14/03166, FPU13/03737 and FPU16/04114), Instituto de Salud Carlos III co-financed by the European Regional Development's funds (FEDER) (RETICSFEDER RD16/0008/0016, Programa Miguel Servet II (CP16/00014) and research project (grant PI17/01700)), Asociación Retina Asturias, Fundación La Caixa, CaixaImpulse program (grant CI17-00048), Comunidad Autónoma de Madrid (grant B2017/BMD-3827), Generalitat Valenciana (PROMETEO/2016/158 and ACIF/2016/055) Generalitat Valenciana-FEDER IDIFEDER/2017/064.

We would also like to thank "Fundación Teófilo Hernando" for its continued support. We thank Miguel Ángel Compañy Sirvent for his technical assistance.

\section{Statement of Ethics}

Animals were handled and maintained according to current guidelines and regulations for the use of laboratory animals (NIH, ARVO and European Directive 2010/63/EU), and comply with the Reporting of in vivo Experiments (ARRIVE) guidelines of animal research, developed by the National Centre for the Replacement, Refinement and Reduction of Animals in Research (NC3Rs) in an effort to minimize their suffering and limit the number of animals used. All procedures received prior approval from the ethics committee for animal care and use at the University of Alicante (UA-07/22/2013). 


\section{Cellular Physiology Cell Physiol Biochem 2020;54:142-159

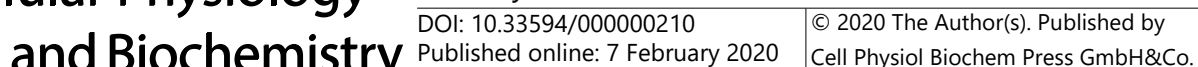 \\ Campello et al.: Novel Nrf2 Inducer ITH12674 Slows Retinal Degeneration}

Author Contributions

NC, AGG, PL and VM designed the experiments, analyzed the results and revised the manuscript. PM and RL designed and synthetized the molecule. LC, OK, AN, LFS, NMG, XSS, IOL and EJ performed the experiments and analyzed the results. All the authors approved the manuscript.

\section{Disclosure Statement}

The authors have no conflicts of interest to declare.

\section{References}

1 Cuenca N, Fernandez-Sanchez L, Campello L, Maneu V, De la Villa P, Lax P, Pinilla I: Cellular responses following retinal injuries and therapeutic approaches for neurodegenerative diseases. Prog Retin Eye Res 2014;43:17-75.

2 Holz FG, Strauss EC, Schmitz-Valckenberg S, van Lookeren Campagne M: Geographic atrophy: clinical features and potential therapeutic approaches. Ophthalmology 2014;121:1079-1091.

3 Yoshida N, Ikeda Y, Notomi S, Ishikawa K, Murakami Y, Hisatomi T, Enaida H, Ishibashi T: Laboratory evidence of sustained chronic inflammatory reaction in retinitis pigmentosa. Ophthalmology 2013;120:e512.

4 Yoshida N, Ikeda Y, Notomi S, Ishikawa K, Murakami Y, Hisatomi T, Enaida H, Ishibashi T: Clinical evidence of sustained chronic inflammatory reaction in retinitis pigmentosa. Ophthalmology 2013;120:100-105.

5 Zhao L, Zabel MK, Wang X, Ma W, Shah P, Fariss RN, Qian H, Parkhurst CN, Gan WB, Wong WT: Microglial phagocytosis of living photoreceptors contributes to inherited retinal degeneration. EMBO Mol Med 2015;7:1179-1197.

6 Zabel MK, Zhao L, Zhang Y, Gonzalez SR, Ma W, Wang X, Fariss RN, Wong WT: Microglial phagocytosis and activation underlying photoreceptor degeneration is regulated by CX3CL1-CX3CR1 signaling in a mouse model of retinitis pigmentosa. Glia 2016;64:1479-1491.

7 Wang X, Zhao L, Zhang Y, Ma W, Gonzalez SR, Fan J, Kretschmer F, Badea TC, Qian HH, Wong WT: Tamoxifen Provides Structural and Functional Rescue in Murine Models of Photoreceptor Degeneration. J Neurosci 2017;37:3294-3310.

8 Cai L, Wang LF, Pan JP, Mi XN, Zhang Z, Geng HJ, Wang JH, Hu SH, Zhang W, Gao Q Wu WT, Luo HM: Neuroprotective Effects of Methyl 3, 4-Dihydroxybenzoate against TBHP-Induced Oxidative Damage in SHSY5Y Cells. Molecules 2016;21:pii:E1071.

9 Zhang J, Xu D, Ouyang H, Hu S, Li A, Luo H, Xu Y: Neuroprotective effects of methyl 3, 4 dihydroxybenzoate in a mouse model of retinitis pigmentosa. Exp Eye Res 2017;162:86-96.

10 Gao X, Talalay P: Induction of phase 2 genes by sulforaphane protects retinal pigment epithelial cells against photooxidative damage. Proc Natl Acad Sci U S A 2004;101:10446-10451.

11 Kang K, Yu M: Protective effect of sulforaphane against retinal degeneration in the Pde6(rd10) mouse model of retinitis pigmentosa. Curr Eye Res 2017;42:1684-1688.

12 Egea J, Buendia I, Parada E, Navarro E, Rada P, Cuadrado A, Lopez MG, Garcia AG, Leon R: Melatoninsulforaphane hybrid ITH12674 induces neuroprotection in oxidative stress conditions by a 'drug-prodrug' mechanism of action. Br J Pharmacol 2015;172:1807-1821.

13 Michalska P, Wojnicz A, Ruiz-Nuno A, Abril S, Buendia I, Leon R: Inclusion complex of ITH12674 with 2-hydroxypropyl-beta-cyclodextrin: Preparation, physical characterization and pharmacological effect. Carbohydr Polym 2017;157:94-104.

14 Noailles A, Kutsyr O, Maneu V, Ortuno-Lizaran I, Campello L, de Juan E, Gomez-Vicente V, Cuenca N, Lax P: The Absence of Toll-Like Receptor 4 Mildly Affects the Structure and Function in the Adult Mouse Retina. Front Cell Neurosci 2019;13:59.

15 Noailles A, Fernandez-Sanchez L, Lax P, Cuenca N: Microglia activation in a model of retinal degeneration and TUDCA neuroprotective effects. J Neuroinflammation 2014;11:186. 


\section{Cellular Physiology Cell Physiol Biochem 2020;54:142-159

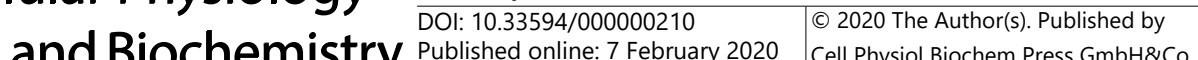 and Biochemistry Published online: 7 February 2020 Cell Physiol Biochem Press GmbH\&Co. KG

16 Di L, Kerns EH, Fan K, McConnell OJ, Carter GT: High throughput artificial membrane permeability assay for blood-brain barrier. Eur J Med Chem 2003;38:223-232.

17 Gong J, Jellali A, Mutterer J, Sahel JA, Rendon A, Picaud S: Distribution of vesicular glutamate transporters in rat and human retina. Brain Res 2006;1082:73-85.

18 Heidelberger R, Thoreson WB, Witkovsky P: Synaptic transmission at retinal ribbon synapses. Prog Retin Eye Res 2005;24:682-720.

19 Schmitz F, Konigstorfer A, Sudhof TC: RIBEYE, a component of synaptic ribbons: a protein's journey through evolution provides insight into synaptic ribbon function. Neuron 2000;28:857-872.

20 tom Dieck S, Altrock WD, Kessels MM, Qualmann B, Regus H, Brauner D, Fejtova A, Bracko O, Gundelfinger ED, Brandstatter JH: Molecular dissection of the photoreceptor ribbon synapse: physical interaction of Bassoon and RIBEYE is essential for the assembly of the ribbon complex. J Cell Biol 2005;168:825-836.

21 Barhoum R, Martinez-Navarrete G, Corrochano S, Germain F, Fernandez-Sanchez L, de la Rosa EJ, de la Villa P, Cuenca N: Functional and structural modifications during retinal degeneration in the rd10 mouse. Neuroscience 2008;155:698-713.

22 Cuenca N, Pinilla I, Sauve Y, Lund R: Early changes in synaptic connectivity following progressive photoreceptor degeneration in RCS rats. Eur J Neurosci 2005;22:1057-1072.

23 Johnson J, Fremeau RT, Jr., Duncan JL, Renteria RC, Yang H, Hua Z, Liu X, LaVail MM, Edwards RH, Copenhagen DR: Vesicular glutamate transporter 1 is required for photoreceptor synaptic signaling but not for intrinsic visual functions. J Neurosci 2007;27:7245-7255.

24 Liang FQ Aleman TS, ZaixinYang, Cideciyan AV, Jacobson SG, Bennett J: Melatonin delays photoreceptor degeneration in the rds/rds mouse. Neuroreport 2001;12:1011-1014.

25 Kong L, Tanito M, Huang Z, Li F, Zhou X, Zaharia A, Yodoi J, McGinnis JF, Cao W: Delay of photoreceptor degeneration in tubby mouse by sulforaphane. J Neurochem 2007;101:1041-1052.

26 Lax P, Otalora BB, Esquiva G, Rol Mde L, Madrid JA, Cuenca N: Circadian dysfunction in P23H rhodopsin transgenic rats: effects of exogenous melatonin. J Pineal Res 2011;50:183-191.

27 Russo R, Varano GP, Adornetto A, Nazio F, Tettamanti G, Girardello R, Cianfanelli V, Cavaliere F, Morrone LA, Corasaniti MT, Cecconi F, Bagetta G, Nucci C: Rapamycin and fasting sustain autophagy response activated by ischemia/reperfusion injury and promote retinal ganglion cell survival. Cell Death Dis 2018;9:981.

28 Kozhevnikova OS, Telegina DV, Devyatkin VA, Kolosova NG: Involvement of the autophagic pathway in the progression of AMD-like retinopathy in senescence-accelerated OXYS rats. Biogerontology 2018;19:223235.

29 Pajares M, Jimenez-Moreno N, Garcia-Yague AJ, Escoll M, de Ceballos ML, Van Leuven F, Rabano A, Yamamoto M, Rojo AI, Cuadrado A: Transcription factor NFE2L2/NRF2 is a regulator of macroautophagy genes. Autophagy 2016;12:1902-1916.

30 Ren J, Yuan L, Wang Y, Chen G, Hu K: Benzyl sulforaphane is superior to sulforaphane in inhibiting the Akt/ MAPK and activating the Nrf2/ARE signalling pathways in HepG2 cells. J Pharm Pharmacol 2018;70:16431653.

31 Agca C, Gubler A, Traber G, Beck C, Imsand C, Ail D, Caprara C, Grimm C: p38 MAPK signaling acts upstream of LIF-dependent neuroprotection during photoreceptor degeneration. Cell Death Dis 2013;4:e785.

32 Ishizuka F, Shimazawa M, Umigai N, Ogishima H, Nakamura S, Tsuruma K, Hara H: Crocetin, a carotenoid derivative, inhibits retinal ischemic damage in mice. Eur J Pharmacol 2013;703:1-10.

33 Sabio G, Davis RJ: TNF and MAP kinase signalling pathways. Semin Immunol 2014;26:237-245.

34 Jiang T, Chang Q, Cai J, Fan J, Zhang X, Xu G: Protective Effects of Melatonin on Retinal Inflammation and Oxidative Stress in Experimental Diabetic Retinopathy. Oxid Med Cell Longev 2016;2016:3528274.

35 Zeng HY, Tso MO, Lai S, Lai H: Activation of nuclear factor-kappaB during retinal degeneration in rd mice. Mol Vis 2008;14:1075-1080.

36 Noailles A, Maneu V, Campello L, Lax P, Cuenca N: Systemic inflammation induced by lipopolysaccharide aggravates inherited retinal dystrophy. Cell Death Dis 2018;9:350.

37 Jiang HR, Lumsden L, Forrester JV: Macrophages and dendritic cells in IRBP-induced experimental autoimmune uveoretinitis in B10RIII mice. Invest Ophthalmol Vis Sci 1999;40:3177-3185.

38 Lehmann U, Heuss ND, McPherson SW, Roehrich H, Gregerson DS: Dendritic cells are early responders to retinal injury. Neurobiol Dis 2010;40:177-184. 


\section{Cellular Physiology Cell Physiol Biochem 2020;54:142-159 \begin{tabular}{ll|l} 
and Biochemistry 10.33594/000000210 & P 2020 The Author(s). Published by \\
Published online: 7 February 2020 & Cell Physiol Biochem Press GmbH\&Co. KG
\end{tabular} \\ Campello et al.: Novel Nrf2 Inducer ITH12674 Slows Retinal Degeneration}

39 Tang PH, Pierson MJ, Heuss ND, Gregerson DS: A subpopulation of activated retinal macrophages selectively migrated to regions of cone photoreceptor stress, but had limited effect on cone death in a mouse model for type 2 Leber congenital amaurosis. Mol Cell Neurosci 2017;85:70-81.

40 Karlen SJ, Miller EB, Wang X, Levine ES, Zawadzki RJ, Burns ME: Monocyte infiltration rather than microglia proliferation dominates the early immune response to rapid photoreceptor degeneration. J Neuroinflammation 2018;15:344.

41 Chidlow G, Ebneter A, Wood JP, Casson RJ: Evidence Supporting an Association Between Expression of Major Histocompatibility Complex II by Microglia and Optic Nerve Degeneration During Experimental Glaucoma. J Glaucoma 2016;25:681-691.

42 Lipski DA, Dewispelaere R, Foucart V, Caspers LE, Defrance M, Bruyns C, Willermain F: MHC class II expression and potential antigen-presenting cells in the retina during experimental autoimmune uveitis. J Neuroinflammation 2017;14:136.

43 Ronning KE, Karlen SJ, Miller EB, Burns ME: Molecular profiling of resident and infiltrating mononuclear phagocytes during rapid adult retinal degeneration using single-cell RNA sequencing. Sci Rep 2019;9:4858.

44 Hartnell A, Steel J, Turley H, Jones M, Jackson DG, Crocker PR: Characterization of human sialoadhesin, a sialic acid binding receptor expressed by resident and inflammatory macrophage populations. Blood 2001;97:288-296.

45 Asano K, Nabeyama A, Miyake Y, Qiu CH, Kurita A, Tomura M, Kanagawa O, Fujii S, Tanaka M: CD169positive macrophages dominate antitumor immunity by crosspresenting dead cell-associated antigens. Immunity 2011;34:85-95.

46 Butovsky O, Siddiqui S, Gabriely G, Lanser AJ, Dake B, Murugaiyan G, Doykan CE, Wu PM, Gali RR, Iyer LK, Lawson R, Berry J, Krichevsky AM, Cudkowicz ME, Weiner HL: Modulating inflammatory monocytes with a unique microRNA gene signature ameliorates murine ALS. J Clin Invest 2012;122:3063-3087.

47 O’Neill AS, van den Berg TK, Mullen GE: Sialoadhesin - a macrophage-restricted marker of immunoregulation and inflammation. Immunology 2013;138:198-207.

48 Bosco A, Romero CO, Breen KT, Chagovetz AA, Steele MR, Ambati BK, Vetter ML: Neurodegeneration severity can be predicted from early microglia alterations monitored in vivo in a mouse model of chronic glaucoma. Dis Model Mech 2015;8:443-455.

49 Crotti A, Glass CK: The choreography of neuroinflammation in Huntington's disease. Trends Immunol 2015;36:364-373. 